\title{
Palabras preliminares
}

Ana Carrasco-Conde y Edgar Maraguat

\section{OpenEdition}

\section{Journals}

\section{Edición electrónica}

URL: http://journals.openedition.org/ref/368

DOI: $10.4000 /$ ref.368

ISSN: 2258-014X

\section{Editor}

EuroPhilosophie Editions

Referencia electrónica

Ana Carrasco-Conde y Edgar Maraguat, «Palabras preliminares », Revista de Estud(i)os sobre Fichte [En línea], 3 | 2011, Publicado el 01 febrero 2011, consultado el 25 septiembre 2020. URL : http:// journals.openedition.org/ref/368; DOI : https://doi.org/10.4000/ref.368

Este documento fue generado automáticamente el 25 septiembre 2020

(c) EuroPhilosophie 


\title{
Palabras preliminares
}

\author{
Ana Carrasco-Conde y Edgar Maraguat
}

1 Dicen que la ruptura entre Fichte y Schelling se consumó en torno a 1800, cuando el segundo le hizo llegar al primero su System des transzendentalen Idealismus. Schelling había igualado en él la dignidad de su Filosofía de la Naturaleza a la de la Filosofía Trascendental: ambas debían estar juntas en el Sistema, completándose, pero no subordinándose la una a la otra. La historia es de sobra conocida: Fichte tardó en responder al que fuera su heraldo entusiasta y sólo lo hizo ante una segunda carta: "Sobre su oposición Filosofía Trascendental y Filosofía de la Naturaleza no estoy aún de acuerdo con usted" (KFA, 2,1, 276) ${ }^{1}$. El tono de la correspondencia entre ambos pensadores fue haciéndose cada vez más tirante hasta que ésta quedó interrumpida definitivamente con la misiva que Schelling envió a Fichte el 25 de enero de 1802. En ella no sólo le reprochaba no leer atentamente sus escritos, sino que también respondía amargamente a su afirmación de que él "no entiende la Wissenschaftslehre mejor de lo que la entiende Friedrich Nicolai" (KFA, 2,1, 405). Como bien ha afirmado Christoph Asmuth "el enfrentamiento entre Schelling y Fichte tiene todo lo necesario para constituir el argumento de un folletín: un comienzo tormentoso, grandes planes, tempranos malentendidos, un poco de intriga, diferencias irreconciliables y un amargo final con el más profundo de los silencios”2. Quizá sea este carácter dramático el que explique que, hasta hace relativamente poco, la controversia entre ambos pensadores haya sobre todo producido el ruido de un conflicto entre partidarios: desde el punto de vista "fichteano" Schelling no dejó de ser un discípulo incómodo de Fichte, incapaz de comprender su sistema y responsable de difundir una comprensión deformada de la Doctrina de la Ciencia. Desde el punto de vista "schellingiano" no sólo Fichte constituye un momento a superar (piénsese en la tesis propalada por Hegel en sus Lecciones sobre la historia de la filosofía, según la cual Fichte y Schelling constituyen los momentos de una evolución que culminaría con el "idealismo absoluto"3), sino también el pasado que se obstina en ser presente y en perseverar erróneamente en un sistema que se ha mostrado ineficiente y anticuado, rígido y muerto. Sin embargo, lo cierto es que, más allá de estas polémicas, la admiración mutua entre estos pensadores fue reconocida en vida por ambos, y no sólo en privado. A la vuelta de los años, Schelling escribió en sus lecciones sobre Historia de la Filosofía Moderna: "Fichte fue para mí, como para todos, 
maestro y predecesor, en la medida en que fue el primero que habló de una filosofía fundamentada en la libertad y el que fundó sobre la autonomía del Yo no sólo [...] la filosofía práctica, sino también la teórica y, por tanto, la filosofía" (Sämtliche Werke, I/ $10,166)$.

Que no dijeron nunca lo mismo sobre lo mismo, que, si hubo coincidencias entre ambos, fueron "libres" (como escribió Kuno Fischer), que el spinozista Schelling tuvo desde el principio planes propios para consumar la revolución kantiana, que la filosofía de Schelling es, si acaso, un desarrollo heterodoxo de la filosofía fichteana o que está formada "a la contra", y que, a pesar de eso, le debe a Fichte los problemas, los términos, las ambiciones y, muchas veces, los argumentos, son obviedades, quizá sólo aparentes, que atraerán permanentemente el interés de la crítica y la historiografía. El presente número de la Revista Estudios sobre Fichte, temáticamente centrado en la relación entre ambos filósofos, lo componen varios intentos de pensar de otro modo y desde otra perspectiva las rupturas y continuidades entre Fichte y Schelling en torno a la Filosofía del Derecho y los asuntos con ella relacionados. En este sentido, los trabajos de Vicente Serrano Marín, Katia Hay, Ana Carrasco Conde, Delia Popa ${ }^{4}$ y Mariano Gaudio tratan de profundizar en los puntos tanto de separación como de confluencia en torno a la cuestión del Derecho y de la Ética. El número concluye con la traducción revisada de la Nueva Deducción del Derecho Natural a cargo de Faustino Oncina ${ }^{5}$, precedida de un riguroso estudio introductorio que da cuenta de la historia de dicho escrito $y$, desde la perspectiva que proporciona el tiempo, de seguir a Christoph Asmuth, del comienzo del drama.

\section{NOTAS}

1. El contenido de esta carta puede consultarse en la traducción al castellano realizada por $\mathrm{H}$. OCHOA EN HTTP://WWW.FILOSOFIA.UCV.CL/PDF/FICH-SCHELLTOTAL.PDF

2. C. ASMUTH: "LETZTE KREUZUNGEN: FICHTE LIEST SCHELLING - SCHELLING LIEST FICHTE”. EN M. GALLAND-SZYMKOWIAK, M. CHÉDIN Y M. BASTIAN WEISS (EDS.): FICHTE - SCHELLING: LECTURES CROISÉES / GEKREUZTE LEKTÜREN, WÜRZBURG, ERGON, 2010, P. 175.

3. Cfr. V. SERRANO MARÍN, ABSOLUTO Y CONCIENCIA. UNA INTRODUCCIÓN A SCHELLING, MADRID, PLAZA Y VALDÉS, 2008, PP. 19-20.

4. El texto de Delia Popa ha sido gentilmente traducido por Glauber Klein. Quede aquí constancia del agradecimiento de los editores.

5. La traducción apareció por vez primera en 1993 en Thémata. Revista de Filosofía, no 11. Agradecemos aquí tanto a Faustino Oncina la amabilidad con la que aceptó nuestra propuesta de incluir en este número su traducción como al director de Thémata, Jacinto Choza, su autorización para hacerlo. 